\title{
Las cartillas de alfabetización de la campaña de 1944-1946 en México
}

The primers of the National Campaign against Illiteracy (1944-1946)

\author{
Carlos Escalante Fernández \\ El Colegio Mexiquense, A.C. \\ cescalante@cma.edu.mx
}

\begin{abstract}
Resumen
En México el analfabetismo sigue siendo uno de los problemas educativos que refleja con más claridad las lacerantes desigualdades existentes y que muestra, a la vez, la incapacidad gubernamental para erradicarlo y garantizar a la totalidad de la población el acceso a uno de los instrumentos de conocimiento más importantes en sociedades de cultura escrita como la nuestra. El analfabetismo ha sido estudiado como parte de la historia de la educación en una entidad, o de la cobertura de la escolarización, o del crecimiento y expansión del sistema educativo o del análisis de los resultados de determinadas políticas en la educación básica. Son pocos los trabajos que se han dedicado a estudiar específicamente la historia del analfabetismo en México, tomándolo como objeto de estudio central, lo que refleja un problema que debe ser resuelto con estudios históricos.

En este artículo pretendo señalar la pertinencia de las cartillas de alfabetización como fuente histórica que permite iluminar ciertos procesos de la historia de la alfabetización y/o del analfabetismo, especialmente en el siglo xx. Para alcanzar el objetivo, centro mi mirada en las cartillas que se elaboraron en la Campaña Nacional contra el Analfabetismo (1944-1946). La campaña fue iniciada a partir de una Ley, conocida como Ley de Emergencia, promulgada en agosto de 1944. En dicha ley se establecía que se debía elaborar una cartilla nacional, un cuaderno de escritura, además de las cartillas bilingües que fueran necesarias para atender a la población indígena monolingüe.
\end{abstract}

Palabras clave: analfabetismo, alfabetización, cartillas, material didáctico, lectoescritura.

\begin{abstract}
IIn Mexico, illiteracy remains an educational problem that reflects the strong inequalities of the population and reveals the government's incapacity to eradicate it and guarantee full access to one of the most important instruments of knowledge in societies such as ours. Illiteracy has been studied in
\end{abstract}

Abstract 
Mexico through the history of education in each state, or as part of studies on the coverage, growth and expansion of the educational system or on the results of certain policies in elementary education. However, few works have been devoted specifically to the study of illiteracy as the focus. This reflects that the problem should be resolved with historical studies. Through this article, I hope to show the relevance of literacy campaign primers as a historical source that sheds light on certain processes of literacy campaigns and on illiteracy itself. I focus on the primers elaborated for the National Campaign against Illiteracy (1944-1946), during the presidency of the General Manuel Ávila Camacho. The campaign began after an "emergency law" was promulgated in August 1944. In this law, the government mandated the creation of a national primer, in the form of a writing notebook. The creation of bilingual primers was introduced for the indigenous population, which was largely monolingual at the time.

Key words: Illiteracy, Literacy campaigns, primers, educational materials as sources, Mexico.

\section{Introducción}

El analfabetismo en México es un problema social y educativo que, aún con las diferentes medidas instrumentadas a lo largo de la historia para abatirlo, refleja desigualdad e impide garantizar el acceso a la lectura y a la escritura a un grupo significativo de mexicanos. El analfabetismo no ha sido estudiado de manera específica en la historiografía de la educación mexicana lo que muestra un vacío que debe llenarse con estudios históricos que contribuyan a entenderlo.

Este artículo tiene como propósito establecer la pertinencia de las cartillas de alfabetización como fuente histórica, a partir de utilizar como ejemplo la descripción de las cartillas elaboradas en la Campaña Nacional contra el Analfabetismo (1944-1946), durante el régimen del general Manuel Ávila Camacho. La campaña se inició a partir de una Ley, conocida como Ley de Emergencia, promulgada en agosto de 1944. En dicha ley se establecía que se debía elaborar una cartilla nacional, un cuaderno de escritura, además de las cartillas bilingües que fueran necesarias para atender a la población indígena monolingüe (artículos 13 y 14 de la ley).

Las cartillas de esta campaña pueden aportar luz historiográfica sobre diferentes tópicos: los debates sobre los métodos de enseñanza de la lectura y la escritura, los debates sobre las lenguas indígenas y la alfabetización en lenguas vernáculas, o sobre los usos y distribución en el país de las cartillas, o acerca de las imágenes que había en sus páginas, las concepciones del analfabeto y del indígena; también se puede realizar un análisis pedagógico y lingüístico de cada una de las cartillas y de sus contenidos ideológicos de exaltación patriótica, democrática y nacionalista; igualmente sería importante un estudio de la gráfica utilizada en las ilustraciones de las cartillas. En este trabajo nos limitaremos a mostrar el proceso de manufactura, tratando de hacer justicia a sus autores, además de presentar el contexto de 
su elaboración y algunas características generales de su contenido. Lo anterior tiene la finalidad de mostrar la pertinencia y relevancia de las cartillas en general como fuentes históricas que deben ser incorporadas de manera central en las diferentes historias que sobre la alfabetización y el analfabetismo escriban en México las historiadoras e historiadores del país.

\section{La cartilla nacional}

No obstante los esfuerzos realizados por los gobiernos posrevolucionarios por erradicar el analfabetismo del país, en 1940 el censo de población indicó que México tenía una población de 19653552 habitantes, de los cuales 9411075 eran analfabetos (se incluía en esta categoría a los que no sabían leer ni escribir, así como a los que sólo sabían leer). Esta cifra representaba el $48 \%$ de la población total. De acuerdo con la Ley de Emergencia, los analfabetos que debían ser alfabetizados eran aquellos hombres y mujeres cuyas edades estuvieran entre los 6 y los 40 años de edad, que, según el censo de 1940, constituían 9411075 personas. Por esa razón, la mencionada ley estableció un tiraje de 10 millones de cartillas de alfabetización.

Con ese tiraje millonario, la Cartilla 1944-1946 que se imprimió para cumplir con la Ley de Emergencia se convirtió en el principal instrumento pedagógico de la Campaña Nacional contra el Analfabetismo. Estaba dividida en tres partes, cada una de las cuales respondía a objetivos de enseñanza y de aprendizaje precisos. La primera, conformada por 30 lecciones, se destinaba al "aprendizaje de las letras y las sílabas directas, inversas y mixtas para iniciar la comprensión (del mecanismo) de la lectura y la escritura". La segunda estaba compuesta de 7 lecciones y pretendía el aprendizaje de las sílabas compuestas (tra, tla, pla, pra, cra, cla, bra, bla, gra, gla, fra, fla y dra) y continuaba con la comprensión de la lectura y la escritura. Finalmente la tercera parte (compuesta de 20 lecciones) tenía como finalidad dominar completamente la lectura y la escritura (SEP, 1944: 4).

Como ya se hizo mención, el artículo 13 de la Ley que dio pie a la campaña especificaba que las cartillas "contendrán las instrucciones sencillas y claras para quien enseñe y el material y los ejercicios necesarios para quien aprenda" (SEP, 1946: 151). Estas instrucciones quedarían plasmadas en las primeras páginas de la cartilla, bajo el título de "A quien utilice esta cartilla".

Luego de varios intentos infructuosos para confeccionar la cartilla nacional, Torres Bodet encontró en las profesoras Dolores Uribe y Carmen Cosgaya Rivas a las personas idóneas para llevar a cabo esa labor. A través de la lectura de las memorias del afamado escritor, diplomático y, en ese momento, secretario de educación, se puede percibir el respeto que mostró por el trabajo de las maestras en la confección de la cartilla.

El objetivo principal que debía cumplir la cartilla era que fuese un instrumento sencillo para el aprendizaje de los analfabetos, pero que, a la vez, resultase igualmente de manejo 
fácil para los alfabetizadores, muchos de los cuales, se suponía, no estaban capacitados pedagógicamente. En palabras de Torres Bodet,

por la calidad de la empresa, y por la impreparación general de los instructores, métodos (de enseñanza del alfabeto) tan modernos [...] infundirían desconciertos en los voluntarios de la campaña. Urgía una cartilla de tipo ecléctico, que sirviese tanto a los profesores recién salidos de alguna escuela normal cuanto a los espontáneos de la enseñanza, inhábiles y bisoños, pero deseosos de cumplir el deber que la ley de emergencia les prescribía. Por otra parte, convenía que algunas lecciones de la cartilla -las que figurasen en los últimos pliegos— iniciarán un diálogo cívico: el que estimábamos necesario para robustecer la unión de los mexicanos (2005: 109).

Bajo esta "consigna" y atendiendo a los preceptos de la Ley de Emergencia las dos profesoras lograron conjugar un instrumento, que logró satisfacer las exigencias de Torres Bodet. Si nos basamos en el testimonio de éste, pareciera que la cuestión de resolver la sencillez de la propuesta pedagógica resultó mérito de las profesoras Uribe y Cosgaya, mientras que la parte del mensaje cívico y moral fue hechura del secretario de educación, pero quizá un análisis pormenorizado del contenido de la cartilla y el cruce de otras fuentes nos podría dar una óptica más completa.

El periódico El Universal, al dar a conocer que la cartilla estaba lista para su distribución nacional, señalaba que, "el espíritu que campea en la cartilla es el de partir del hogar, como tema de escritura y lectura, seguir con las relaciones con el medio ambiente (el campo, los animales domésticos y salvajes, los amigos, la ciudad, la escuela) y termina con temas relacionados con nuestra historia, siendo el último el Himno Nacional".

La distribución de la cartilla nacional en el territorio del país se llevó a cabo en los últimos meses de 1944 y los dos primeros de 1945. Al final de febrero de 1945 se repartieron gratuitamente siete millones y medio de cartillas de lectura y siete millones y medio de cuadernos de escritura (Torres Bodet, 1948: 260). No se sabe, cuál fue el destino de los ejemplares restantes (dos millones y medio).

En 1965, la Cartilla se reeditó para apoyar los trabajos de alfabetización en el sexenio de Gustavo Díaz Ordaz.

\section{Las cartillas bilingües}

En el artículo 14 de la Ley de Emergencia se señalaba que debido a la importancia "de cada uno de los grupos de indígenas que habitan en el territorio nacional y del predominio que en ellos tiene su idioma nativo... [la Secretaría de Educación] determinará los procedimientos 
técnicos adecuados e imprimirá las cartillas bilingües que fueren necesarias para llevar a cabo, como complemento de la campaña contra el analfabetismo, una labor de enseñanza del español realizado en aquellos grupos por brigadas de instructores especiales, capacitados merced a cursos intensivos de adiestramiento" (SEP, 1946: 151).

Así, se consideró pertinente confeccionar seis cartillas para atender a los indígenas monolingües de grupos hablantes particulares localizados en regiones geográficas específicas: tarascos, tarahumaras, mayas de Yucatán y Campeche, nahuat del norte de Puebla, otomíes del Valle del Mezquital y parte de Querétaro y náhuatl del estado de Morelos. Estados como Oaxaca y Chiapas, con una significativa población indígena y altos índices de analfabetismo no fueron considerados para confeccionar cartillas bilingües acordes a los grupos indígenas de esas entidades.

Las cartillas bilingües tuvieron, en el tiempo de su manufactura, un derrotero diferente al de la cartilla en español. Tres tipos de problemas hubo que enfrentar en su manufactura: el lingüístico, el pedagógico y el de la exposición gráfica. Para encararlos, se conformaron equipos especializados en estas tres áreas problemáticas. Además de estos problemas, el proyecto de cartillas especiales tuvo opiniones contrarias, que no compartían la idea del empleo de lenguas indígenas en la enseñanza (Greaves, 2008: 231). Años después, Torres Bodet lo recordaría de esta manera:

\begin{abstract}
respecto a la castellanización de los indígenas monolingües, se manifestaban en la propia secretaría, dos opiniones adversas. Los conservadores querían que se alfabetizara desde luego a los indios, en español. Invocaban, para ello, la circunstancia -indiscutible desde el punto de vista jurídico- de que ése es el idioma oficial de México. Los otros, menos tradicionalistas (o tradicionalistas, en el correcto sentido histórico), aspiraban a que se alfabetizara primero a los indios en su lengua materna, a fin de castellanizarlos después, sobre más firmes bases gramaticales (2005: 112).
\end{abstract}

Así, Torres Bodet estableció el Instituto de Alfabetización en Lenguas Indígenas, bajo la dirección del profesor Alfredo Barrera Vázquez, yucateco, hablante de maya, estudioso de la cultura maya y, en palabras de Torres Bodet, "un hombre de talento y de verdadera capacidad" (2005: 113). Los trabajos del Instituto iniciaron en agosto de 1945, con unos cursos destinados a maestros bilingües que servirían posteriormente de sostén de la alfabetización de los indígenas monolingües. Según lo planeó, Barrera Vázquez, e interpretó Torres Bodet, lo que se trataba era "de proporcionar a un grupo de maestros normalistas, bien escogido, las nociones fundamentales para aprovechar con rapidez y con eficacia los textos que hayan de redactarse a fin de que los indígenas, sin prescindir de su lengua nativa, con la que se encuentran ligados por vínculos entrañables de familia, de origen, de historia, de geografía y de convicción, aprendan el castellano y adquieran el uso del alfabeto". Cada uno de estos 
maestros, luego de la capacitación, iría a alguna entidad a impartir estos cursos a 30 maestros rurales y bilingües para que éstos fungieran como instructores capaces (Torres Bodet, 1948: 273)

A pesar de los ataques al Instituto, según las memorias de Torres Bodet, en 1946 aparecieron cuatro cartillas diferentes: la maya en enero, la tarasca en abril, la de los otomíes en junio y, finalmente, en agosto, la de náhuatl destinada al norte de Puebla (Torres Bodet, 2005: 113).

Como apunta Cecilia Greaves, los problemas en la elaboración de estas cartillas "empezaron con el alfabeto. El maya, el náhuatl y el tarasco, con una larga tradición literaria, podían trascribirse a las grafías latinas del español sin dificultad, no así el otomí, cuyos sonidos no siempre tenían equivalentes en castellano" (Greaves, 2008: 232).

La cartilla maya-español fue redactada por el profesor yucateco Silio Rodolfo Escalante, las ilustraciones estuvieron a cargo de Angelina Beloff, pintora rusa avecindada en México, y del artista plástico Gabriel Fernández Ledesma, quien en 1944 había recibido la beca Guggenheim. La cartilla constaba de 100 páginas y tuvo un tiraje de 150000 ejemplares (Corona y de Santiago, 2011: 143). Además de los héroes nacionales, en esta cartilla se incluyó a Andrés Quintana Roo y a Felipe Carrillo Puerto, "su presencia fue señalada, tanto por el redactor pedagógico, profesor Escalante, como por la ilustradora, Angelina Beloff" (Torres Bodet, 2005: 113). El título completo de la cartilla, Cartilla maya-español para los monolingües mayas de Yucatán, Campeche y Quintana Roo, indicaba claramente el ámbito geográfico de acción del esfuerzo alfabetizador.

La portada de la cartilla mostraba a un grupo de mayas, con sus atuendos propios, hombres y mujeres, niños y adultos, sentados y con cartillas en sus manos, en actitud de estar leyendo de manera silenciosa. La cartilla nacional presentaba una imagen similar en la que aparecía una familia campesina mestiza con la misma actitud que la cartilla maya.

Las dos cartillas de nahuátl tuvieron un tiraje de 100000 ejemplares cada una. En la ficha bibliográfica se omitieron, a diferencia de la maya, los datos de redactores e ilustradores, al señalarse que estuvieron a cargo del taller de dibujo del Departamento de Publicidad y Propaganda de la Secretaría de Educación.

La cartilla otomí-español destinada a los monolingües del Valle del Mezquital en Hidalgo y de una parte del estado de Querétaro tuvo un tiraje de 50000 ejemplares y constaba de 140 páginas. La redactora fue Sara Flores Sánchez y el taller de dibujo ya mencionado se encargó de las ilustraciones (Corona y de Santiago, 2011: 143).

Finalmente, la cartilla en tarasco, Cartilla tarasco-español para los monolingües de la zona tarasca, se confeccionó a partir de la experiencia previa del Proyecto Tarasco (Greaves, 2008: 231). No se sabe quiénes fueron los que intervinieron en su redacción (sucede lo mismo con la cartilla tarahumara-español). Su tiraje fue de 25000 ejemplares y contiene casi 200 páginas (Corona y de Santiago, 2011: 143). En sus páginas se destacó la labor de Vasco de Quiroga. 
En todas las cartillas mencionadas, se incluyeron, según recordaba Torres Bodet, "algunas de las páginas cívicas de la cartilla nacional". Pero, a la vez, y por sugerencia de los redactores pedagógicos, se mencionaron realidades representativas de cada región, como árboles, animales domésticos, frutas conocidas, trajes, costumbres y paisajes típicos (Torres Bodet, 2005: 113).

Lamentablemente, las cartillas bilingües, al parecer, se utilizaron poco, pues cuando ya se habían distribuido, el sexenio de Ávila Camacho concluyó y el Instituto de Alfabetización en Lenguas Indígenas interrumpió su labor, según la versión de Jaime Torres Bodet, por lo que pese a que la campaña se prolongó, por decreto, en el sexenio alemanista, no hubo continuidad en el trabajo por la interrupción del Instituto que había diseñado las cartillas bilingües.

No obstante los resultados limitados que arrojó la campaña en el sexenio avilacamachista, se debe destacar que uno de sus legados fue el trabajo pionero de confección de cartillas, trabajo en el que se buscó contar con instrumentos sencillos y eficaces para la labor de los alfabetizadores y para interesar a los alfabetos participantes en la campaña. Allí radica la importancia de estas primeras cartillas y su pertinencia como fuente histórica para comprender no sólo la campaña particular de 1944-1946, sino también para entender los problemas pedagógicos y lingüísticos que debieron enfrentarse en el proceso de elaboración de estas cartillas bilingües, cuestiones que siguieron siendo parte de la polémica lingüística y cultural en las décadas siguientes. Respecto de la cartilla nacional, su importancia es similar y como fuente aporta información no sólo para la campaña de 1944-1946 sino también en la campaña impulsada años después pues, como se sabe, se reeditó para utilizarse como instrumento didáctico. Finalmente también puede ser válida su aportación en el estudio de las políticas editoriales impulsadas por la SEP y para el estudio de instrumentos didácticos que, como los manuales escolares, tuvieron una finalidad específica y contribuyeron a introducir a muchos mexicanos en la cultura de la palabra escrita.

\section{Fuentes}

\section{Hemerográficas}

El Universal, México, noviembre de 1944

\section{Bibliográficas}

Araiza, Sandra Omelina (2007) "La segunda campaña alfabetizadora a través de las fotografías de los Hermanos Mayo, 1944-1946", Tesis de maestría en Historia, Universidad de Colima, Colima.

Beloff, Angelina (1986). Memorias, Universidad Nacional Autónoma de México-Secretaría de Educación Pública, México.

Colín, Laura Cristina (2010), "La cartilla de alfabetización de 1944, un libro de texto destinado a los adultos", Revista ISCEEM, núm. 9, enero-junio, pp. 23-30. 
Corona, Sarah y Arnulfo de Santiago (2011), Niños y libros. Publicaciones infantiles de la Secretaría de Educación Pública, México, Secretaría de Educación Pública.

Greaves, Cecilia (2008), Del radicalismo a la unidad nacional. Una visión de la educación en el México contemporáneo 1940-1964, México, El Colegio de México.

Reynoso, Jenaro y María Guadalupe Mendoza (2004), "'Si a tu patria quieres servir, debes enseñar a leer y escribir', la campaña contra el analfabetismo en Toluca y Tenancingo 1944-1946", Quadrivium, núm. 17-18, pp. 198-213.

Secretaría de Educación Pública (SEP) (1944), Campaña Nacional contra el Analfabetismo. Cartilla 1944 1946, México.

(1946), La obra educativa en el sexenio 1940-1946, México, Secretaría de Educación Pública. , e Instituto de Alfabetización en Lenguas Indígenas (1946), Cartilla maya-español para los monolingües mayas de Yucatán, Campeche y Quintana Roo, México, Secretaría de Educación Pública-Instituto de Alfabetización en Lenguas Indígenas.

Torres Bodet, Jaime (1948), Educación y concordia internacional. Discursos y mensajes (1941-1947), México, El Colegio de México, pp. 255-282.

(1985), "La alfabetización defiende a México", en Valentina Torres Septién (comp.), Pensamiento educativo de Jaime Torres Bodet, México, Secretaría de Educación Pública-El Caballito, pp. 69-71.

(2005), "Iniciación de la campaña contra el analfabetismo", en Textos sobre educación, selección, introducción y notas de Pablo Latapí, México, Consejo Nacional para la Cultura y las Artes, pp. 102-117.

Torres Septién, Valentina (1994), "En busca de la modernidad, 1940-1960", en Historia de la alfabetización y de la educación de adultos, t. 3, El México de los grandes cambios. La época contemporánea, México, Instituto Nacional para la Educación de los Adultos-El Colegio de México, pp. 469-544.

Carlos Escalante Fernández. Es Profesor investigador de El Colegio Mexiquense, A.C.; doctor en Ciencias con especialidad en Investigaciones Educativas. Departamento de Investigaciones Educativas, Cinvestav-IPN. Líneas de investigación: Historia de la educación en México, siglo XIX y primera mitad del XX. Actualmente realiza una investigación sobre las concepciones de analfabetismo de pedagogos mexicanos. Algunas publicaciones: "Francisco Larroyo y la enseñanza de la historia de la educación en México", en José Gondra y José Claudio Sooma Silva (coords.)(2011), Historia da educaçao na America Latina: ensinar \& escrever, Editora da Universidade do Estado do Rio de Janeiro; Alicia Civera Cerecedo, Juan Alfonseca Giner de los Ríos y Carlos Escalante Fernández (coords.) (2011), Campesinos y escolares. La construcción de la escuela en el campo latinoamericano (siglos XIX y XX), México, El Colegio Mexiquense, A.C.-Miguel Ángel Porrúa (Serie Las Ciencias Sociales); Carlos Escalante Fernández y Antonio Padilla Arroyo (1998), La ardua tarea de educar. Orígenes y formación del sistema educativo en el estado de México, Toluca, Instituto Superior de Ciencias de la Educación del Estado de México-Sindicato de Maestros al Servicio del Estado de México.

Recibido: 9 de marzo de 2012

Aceptado: 15 de agosto de 2012 